\section{The Positive Implications of Intentional Feedback}

\author{
Kera Ackerman and Channon Horn
}

Journal of Special Education Preparation 1(1), 16-24

(C) Ackerman and Horn

Licensed with CC-BY-NC-ND 4.0 License DOI: 10.33043/JOSEP.1.1.16-24

openjournals.bsu.edu/JOSEP

\begin{abstract}
Positive and constructive feedback is a high leverage practice that can be learned and practiced through scaffolded and structured experiences. Teaching preservice candidates to provide effective feedback is an efficient way to increase P-12 students' learning and behavioral outcomes. Teacher educators can craft experiences for their preservice teachers that offer rich coursework experiences, practice-based opportunities, and aligned clinical placement. Using the scaffolded approach provided in this article, teacher educators can ensure these experiences are robust and aligned with evidence-based pedagogy.
\end{abstract}

\title{
Keywords:
}

aligned clinical placement, feedback, high leverage practice, practice-based opportunities, teacher preparation

Several preservice teachers discuss their most recent lessons that they taught earlier in the week in their advanced clinical field placements. This is their final semester before student teaching, and they are refining their teacher behaviors. Toby comments, "I feel like I say, 'Good job' too much-I know it is good to praise their effort, but sometimes I even say, 'Good job trying' when they give the wrong answer because I can't think of what else to say!"

"Me, too! I notice if I compliment someone on their behavior, like thanking Josiah for raising his hand and waiting to be called on, the other students will automatically put their hands up, too. I am not able to really give targeted instructive or corrective feedback on the spot," shares Mariah.

The Council for Exceptional Children (CEC) and the Collaboration for Effective Educator Development, Accountability, and Reform (CEEDAR) center have developed a set of 22 high leverage practices (HLPs) that can be effectively taught, practiced, and learned by preservice teachers and will result in increased learning outcomes for the P-12 learners they are teaching (McLeskey et al., 2017). The HLP: Provide positive and constructive feedback to guide students' learning and behavior (McLeskey et al., 2017) was deemed so impactful, it was listed under both the instruction practices domain (HLP 8) and social, emotional, behavioral practices domain (HLP 22). While the ultimate goal is mastery of the practice, it is understood that becoming an expert is an ongoing process. Therefore, we would be remiss if we did not put into perspective what the inten- tion of education preparation programs (EPPs) should be. Using Dreyfus's (2004) framework on the stages of expertise as a guide, the intention should be to move the preservice teacher from novice (e.g., can identify the practice) to advanced beginner (e.g., gains experience in the practice) in their use of this powerful HLP. Brownell et al. (2019) describe the shift from novice to advanced beginners as moving from inert knowledge to being able to "apply their knowledge of rules and strategies more flexibly" (p. 339). The challenge, then, is to establish a program that allows preservice teachers to practice these skills in a systematic manner by establishing a clear foundational knowledge of feedback and then providing scaffolded opportunities to embed this HLP into their lesson planning and instruction.

\section{Establish Foundational Knowledge of HLPs 8 \&}

22: Provide Positive and Constructive Feedback to Guide Students' Learning and Behavior

Positive and constructive feedback is identified as one of the most effective teacher practices and can result in increased positive learning and behavior outcomes for P-12 learners (e.g., Hattie \& Timperley, 2007; Hattie, 2009; McLeskey et al., 2017; Waack, 2018). It is also an efficient practice, which with proper planning can take very little time to implement during instruction. As an integral part of the stimulus-response-consequent learning trial (Skinner et al., 1996), feedback is the consequent and can provide behavior-specific praise, confirmation of a correct response (i.e., instructive feedback) or correction for an incorrect response 
(e.g., corrective feedback). It can be given in written or verbal form. Because feedback is dependent on the learner response, its proper use is reliant on several factors. McLeskey et al. (2017) identified six components of effective feedback: timely, contingent, genuine, meaningful, age appropriate, and rates commensurate with task and phase of learning. As preservice teachers are learning to identify effective feedback statements in their practice, they can use the checklist in Table 1 to verify if their feedback statements meet these criteria. Each type of feedback is further defined below.

Table 1. Effective Feedback Checklist

\begin{tabular}{|c|c|}
\hline Component & Description \\
\hline Timely & $\begin{array}{l}\text { Feedback is given im- } \\
\text { mediately following the } \\
\text { target behavior. }\end{array}$ \\
\hline Contingent & $\begin{array}{l}\text { Feedback is given only } \\
\text { when the target behavior } \\
\text { is emitted. }\end{array}$ \\
\hline Genuine & $\begin{array}{l}\text { Feedback is delivered in } \\
\text { a sincere manner, and in } \\
\text { private when appropri- } \\
\text { ate. }\end{array}$ \\
\hline Meaningful & $\begin{array}{l}\text { Feedback is direction re- } \\
\text { lated to the learning goal } \\
\text { or objective of lesson. }\end{array}$ \\
\hline Age appropriate & $\begin{array}{l}\text { Feedback is delivered } \\
\text { in a manner that aligns } \\
\text { with the learner's age } \\
\text { and context (e.g., high } \\
\text { five for an elementary } \\
\text { aged student). }\end{array}$ \\
\hline $\begin{array}{l}\text { Rate commensurate } \\
\text { with task and phase of } \\
\text { learning }\end{array}$ & $\begin{array}{l}\text { Feedback is given fre- } \\
\text { quently during acquisi- } \\
\text { tion learning and faded } \\
\text { as the student moves } \\
\text { through the phases of } \\
\text { learning. }\end{array}$ \\
\hline
\end{tabular}

\section{Behavior-Specific Praise}

Behavior-specific praise is identified as a potentially evidence-based practice based on the Council for Exceptional Children guidelines (Royer et al., 2019). At its core, behavior specific praise increases desired learner behaviors. It differs from general praise (e.g., "good job!") in that it provides specific feedback to the class or individual learner on a correct academic or social behavior. General praise rarely results in the same increase in desired behavior (Hattie \& Timperly, 2007).

As noticed by preservice teacher Toby in the opening vignette, providing general praise is an easy trap to fall in. The novice preservice teacher Mariah noticed an increase in a desired behavior (i.e., hand raising) when she offered behavior-specific praise to a target student.

Preservice teachers can be taught to identify and implement behavior-specific praise in their instruction by using the following formula: student + behavior + positive statement = behavior-specific praise (e.g., "Josiah, thank you for raising your hand and waiting, that helps our class run so much more smoothly!"; see Figure 1 for the components of behavior-specific praise).

Because behavior-specific praise can be so easily inserted into instruction, it is efficient and does not interrupt the teaching routine (Royer et al., 2019). Behavior-specific praise decreases the teacher's time in correcting academic errors and undesired behaviors, and increases the academic learning time, learner confidence, and positive teacher-learner relationships (Royer et al., 2019). Preservice teachers should target approximately six behavior-specific praise statements per 15-min of instruction (Myers et al., 2011).

Figure 1. Three Components of Effective Behavior-

Specific Praise

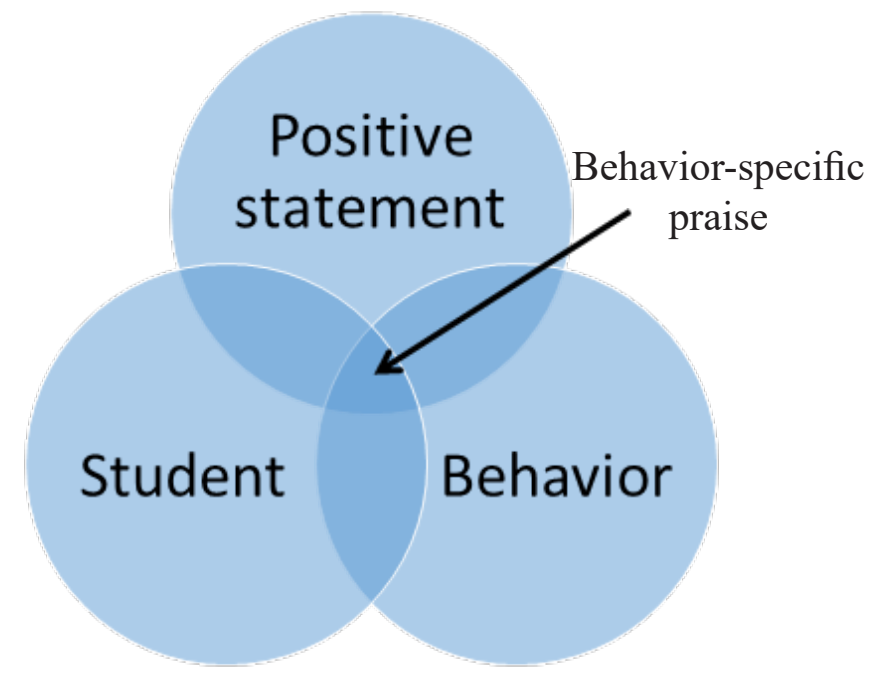

\section{Instructive Feedback}

Instructive feedback is a positive statement given when the learner provides a correct response that both confirms the response and provides additional informa- 
tion to the learner. Providing instructive feedback increases the efficiency of instruction because within one learning trial, learners are reinforced for their correct response and exposed to information that will be useful in the future or makes connections to previously learned content. It is a versatile strategy that can be used across grade levels, content areas, and with all ability levels (Albarran, \& Sandbank, 2018).

To provide instructive feedback in an effective manner, the preservice teacher should confirm the correct response, and then emphasize previously learned concepts or add new or non-target information (see Figure 2 for the components of instructive feedback). Wertz et al. (1996) suggested asking two questions to narrow potential instructive feedback: a) is there important information that is not being taught directly? and b) is there upcoming information?

Figure 2. Components of Instructive Feedback

Confirm the

correct learner

response

Connect to previous learning,

expand to upcoming learning, link

to a parallel concept, or provide

new non-target information

Increased

learner

outcomes

\section{Three Types of Instructive Feedback.}

Werts et al. (1996) provided three types of instructive feedback: expansion, parallel, and novel. Expansion feedback expands upon the students' response by providing additional information related to the response.

Jenna, a preservice teacher, provides the following example of expansion feedback, "Jeremiah answered 'c' says / $k$ /, so I responded, 'That's right, 'c' says / $k /$ and soon we will learn that 'c' can also make the /s/ sound!"

Jenna used her knowledge of upcoming lessons to provide expansion instructive feedback to Jeremiah, preparing him for future learning. Parallel instructive feedback provides a different form of the stimulus or prompt that would require the same response.

In his lesson plan reflection, Juan highlights an example of parallel feedback, "I told Jessy she was correct, the letter was ' $B$ ' then I showed her the lowercase letter and told her it was also ' $b$ '.",

Juan was able to give additional information that was not yet part of Jessy's repertoire thereby setting the stage for upcoming lessons. Novel instructive feedback presents information that is unrelated to the targeted skill.

Preservice teacher Kait identifies novel feedback in her lesson reflection, "After Josh successfully shared his rocket science fair project, I added that NASA's ARTEMIS mission hoped to put people on the moon again."

\section{Corrective Feedback}

As was evident in the opening vignette, preservice teachers can struggle to respond to learners who do not provide correct responses. Corrective feedback is a statement that corrects an incorrect response and gives the learner specific information so they can correct their mistake. It is powerful because it provides a scaffold that will lead them to emit the correct response so that reinforcement can be given (see Figure 3 for the components of corrective feedback). This is quite different from a reprimand (e.g., "no, that isn't right") which does not give the learner the information needed to correct the error or allow them to access the contingent reinforcement.

Preservice teacher Beth-Ann gives this example of corrective feedback related to a social behavior, "Shevesa was texting on her phone during the guest speaker. I quietly walked up to her and told her she needed to put her phone away, get out her notebook, and make eye contact with the speaker. As soon as she complied, I thanked her." 
Figure 3. Components of Corrective Feedback

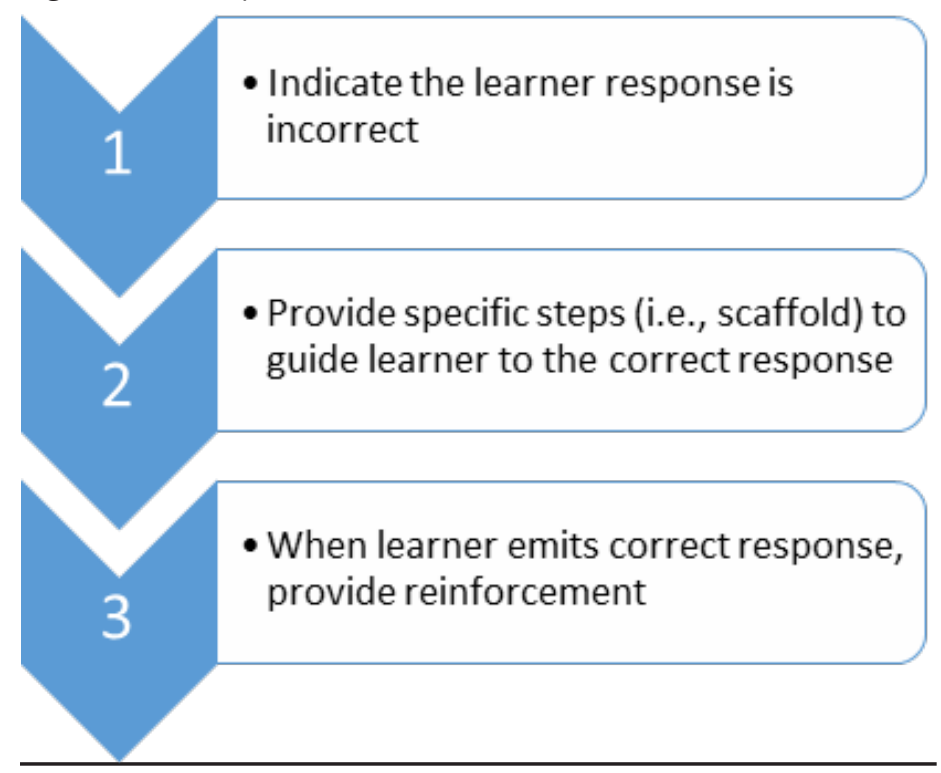

Provide Opportunities for Preservice Teachers

\section{to Embed Intentional Feedback}

Brownell et al. (2019) provide a continuum of effective practice-based opportunities in teacher education which acknowledge that the majority of the learning preservice teachers do in a college classroom is apart from where they will ultimately apply their learning. Even though this is the case, embedding intentional practice-based opportunities into the coursework can lead to increased preservice teacher and P-12 learner outcomes. There are prominent features that should be facilitated with fidelity if preservice teachers are going to progress from novice to advanced beginners into their first year of teaching with efficiency: modeling, feedback through coaching, and self-analysis of performance (Brownell et al., 2019). By carefully selecting the practices that best provide opportunities for preservice teachers to practice newly learned teaching skills, and refining coursework and clinical field placements to embed these practices, teacher educators can scaffold their preservice teachers from college students to first year teachers.

\section{Analyze Expert Models Using Video}

Armed with foundational knowledge of effective feedback and operational definitions of the types of positive and constructive feedback (i.e., behavior-specific praise, instructive feedback, corrective feedback), preservice teachers can glean additional experience by analyzing teachers implementing feedback via video cases. Analyzing teacher practice through video case analysis can improve preservice teachers' ability to identify and understand instructional practice (Thomas \& Rieth, 2011). By viewing videos of teacher practice with their preservice teachers, teacher educators can guide the discussion regarding decisions teachers make during instruction and provide a scaffold for preservice teachers to identify the key components of practice. Using Figures 1, 2, and 3 and the checklist in Table 1, preservice teachers can watch these models and identify the components of significant learning trials and analyze the teacher feedback and subsequent student learning outcomes. Teacher educators can further connect the video models to their preservice teacher practices by having the preservice teachers use a common rubric to analyze the models (e.g., Explicit Instruction Rubric provides excellent opportunity for analysis, see Moylan et al., 2017). Embedding the video models into class instruction allows opportunities for the teacher educator to pause the video, guide discussion on the practice, and model reflection. Various video model resources are available to teacher educators including the ATLAS cases provided by the National Board for Professional Teaching Standards which can be accessed for a fee (https://atlas.nbpts.org/) and the free High Leverage Practice video series (https://highleveragepractices.org/). By providing preservice teachers with models, teacher educators are establishing a foundation on which the preservice teachers can build their skill set.

\section{Embed feedback Statements into Lesson}

\section{Planning}

Preservice teachers need to plan ahead to embed intentional feedback during instruction because initially this skill does not come naturally. One strategy preservice teachers can use is to include a table in their lesson plan procedures (see Figure 4 for an example of feedback embedded into procedures). Within this table, preservice teachers list each planned opportunity to respond and possible behavior specific praise, instructive feedback, and corrective feedback statements to be used as the consequent. When creating this table, preservice teachers should closely review the content standards to familiarize themselves with previously learned standards, the standard being taught, and upcoming standards that could be used to shape the feedback statements. Feedback should be tailored to the needs of the learner and the goal/ objective of the lesson, meaning the preservice teacher must have a deep understanding of the students' present levels of understanding and learning goals. Additionally, they should 
Figure 4. Excerpt of Lesson Plan Procedures with Potential Feedback Statements

Teacher: Pick a number between 0-5 and say, "Kylen, I would like you to place the touch point stickers on the (insert number) just like I showed you. Remember, the stickers represent each touch point." (Repeat this until all numbers have touch points).

Correct Response $\quad$ Provide behavior-specific praise: "Excellent work, you remembered the touch points for the (insert number) and put the stickers in the right place! Now we can count them!"

Incorrect Response

Provide corrective feedback: "Let's check this touch point. Remember, for (insert number) we need to place a touch point (point to location) here. Put your sticker here." Student responds correctly, "Yes, the touch points are now correct! Nicely done."

Teacher: "Now that you have placed the touch points on the numbers, let's count them. Watch me count first, then you will count." (Teacher models). "Your turn. Kylen, count the (insert number)."

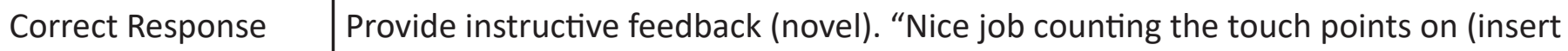
number). Let me show you how the number (insert number) is written in word form!" (Write word on marker board).

Incorrect Response

"Remember, we begin at 1 and count on as we touch each touch point. Start here (point to location) and count, 1 ... (insert number)." Student responds correctly, "Great job touching each touch point and counting."

anticipate misunderstandings of the content and align their feedback statements accordingly.

As the preservice teachers move from novice to advanced beginner, they may find it is more effective to write potential feedback statements on sticky notes to place in teaching manuals as a prompt. By reviewing the six components of effective feedback from McLeskey et al. (2017) preservice teachers ensure their feedback will have the most impact (see Table 1 for the six components).

\section{Practice Feedback Through Role Play and}

\section{Coaching}

Literature supports the use of role play (i.e., rehearsal, microteaching) to practice teacher behaviors in a controlled environment with coaching to shape the expected behaviors (Brock \& Carter, 2017; Grossman, 2005; Kraft et al., 2018). Practice opportunities should be repetitive in nature and allow learners repeated opportunities to acquire and implement professional skills. Often when engaged in role play, preservice teachers will request "one more try." It is in those moments of repetitive interactions that positive growth is frequently evidenced. Teaching involves the preservice teacher implementing complex skill sets in complex environments. Therefore, scaffolded practice opportunities ensure preservice teachers have the ability to implement instruction initially in small, controlled chunks, prior to implementing these complex skills in P-12 environ- ments that frequently hold many unexpected circumstances.

Practice opportunities can be conducted in peer to peer arrangements or through mixed virtual reality simulations. In both arrangements, preservice teachers prepare a short lesson with detailed procedures (see Figure 4 for an example of feedback embedded into procedures). Then, they teach these lessons to either a small group of peers that act as P-12 learners (i.e., peer to peer) or via mixed reality simulations where avatars serve as the learners (e.g., Hudson et al., 2019; Peterson-Ahmad, 2018). During these practice opportunities, preservice teachers have the ability to make corrections to their practice guided by immediate coaching from the teacher educator. Preservice teachers can use a designated rubric which is aligned to the expected components of feedback to evaluate each other's feedback statements. These practice opportunities also provide ample time to identify additional behavior-specific praise, instructive feedback, and corrective feedback statements that can be embedded into instruction. The preservice teachers' behavior is shaped in a low stress, low stakes environment where the consequence of making a mistake does not impact the learning of a P-12 student.

Toby explained, "teaching the lesson to the avatars first allowed me to stay on track with my lesson plan and adjust when the fire alarm went off unexpectedly when I was in the classroom with the little kiddos. I was confident knowing I could quickly get them back 
to task."

Intentional implementation of cohesive practice opportunities assist candidates in progressing from the acquisition to fluency phase when learning how to implement HLPs across content areas and support categories. The use of repeated opportunities that are scaffolded and cohesive will only make the implementation of learned professional practices and skills that much more generalizable when they are strategically aligned to approximate the authenticity found in the P-12 classroom.

\section{Generalize Feedback to Clinical Field Placements}

In order for EPPs to be truly successful they must ensure that the skills acquired during college coursework and practiced through role playing are generalized into the P-12 environment. The train and hope philosophy must be abandoned if they desire to produce preservice teachers that are adequately prepared for the realities of the classroom environment (Markelz et al., 2017). Therefore, it is imperative that teacher educators are intentional in programming for the generalization of skills across content areas, grade levels, and disability categories. Unfortunately, this is not new information as Baer et al. (1968) indicated more than 50 years ago that generalization strategies must be actively programmed throughout EPPs instead of passively expecting them to occur. Although there is no debate concerning the need for generalization of skills to occur, how to make this a reality continues to be a lofty, yet attainable, endeavor.

Aligned clinical field experiences are one of the most promising practices to promote the generalization of preservice teacher skills from college coursework into authentic settings with P-12 learners. These experiences allow preservice teachers the opportunity to develop, implement, and respond to student needs in real time after having acquired and practiced the necessary skills to educate students with diverse learning needs through traditional coursework opportunities. Aligned clinical field experiences require a collaborative, communicative environment where teacher educators intentionally select cooperative partners who model the use of HLPs on a consistent basis and uphold candidates to previously established expectations.

Ongoing collaboration with invested personnel is a critical component to preservice teachers' success in clinical field experiences. The National Council for Accreditation of Teacher Education's Blue Ribbon Panel on Clinical Preparation and Partnerships for Improved
Student Learning (NCATE, 2010) urged EPP's to develop programs that are clinically based and connected to academic coursework. Facilitating a high touch philosophy where each member of the team (e.g., cooperating teacher, teacher educator, university supervisor, preservice teacher) is valued for their contribution is an integral part of the process. It is imperative that the teacher educator communicate which professional strategies are being covered to the university supervisor and P-12 partner.

In one favorable instance, the university supervisor is sharing the significant improvement evidenced in Jenna's ability to provide instructive feedback to her learners via anecdotal records captured during direct observation. Her course instructor replies "This is so encouraging! We covered that topic again last week in our microteaching segment. It is good to hear the transfer of skills is occurring."

Dropping a few lines to your collaborative and supervising partners does not need to be time or labor intensive, it does however, need to be timely and intentional in nature.

\section{Reinforce Feedback Through Self-Analysis and}

\section{Reflection}

Throughout the entire sequence of developing foundational knowledge, analyzing video models, practicing through role play, and generalizing to clinical field placements, preservice teachers should engage in deep reflection of practice. It is the serious and consistent consideration of one's actions and the impact on others that creates positive change. "Reflectivity is a cornerstone for effective instructional decision making and advocacy," (Etscheidt et al., 2012, p. 21). Therefore, EPPs should deliberately incorporate these practices into all facets of coursework and aligned clinical field experiences.

Preservice teachers can reflect on expert teachers' use of feedback while viewing video models and observing in their clinical field placements. Once the preservice teachers have a clear understanding of the components of feedback and types of positive and constructive feedback (i.e., behavior-specific praise, instructive, corrective) they should be directed to reflect on the impact feedback statements have on the P-12 learners' outcomes. Lessons taught during both role play and generalization in clinical field placements lend themselves to rich reflection opportunities. Video assessment tools, such as GoReact, can be used to share 
Table 2. Reflection Questions

\begin{tabular}{ll}
\hline Component & Question \\
\hline Behavior-specific praise & $\begin{array}{l}\text { Did you provide behavior-specific praise during your lesson? If yes, give an ex- } \\
\text { ample and the learner response. If no, give one example that would have been } \\
\text { appropriate in the lesson and the potential learner response. }\end{array}$
\end{tabular}

Instructive feedback

Did you use instructive feedback? If so, list it here. Was it parallel feedback, novel, or extension? How did it relate to content standards? What was the learner response? If you did not, provide an example of a potential instructive feedback statement that could be used. What do you anticipate the learner response to be?

Corrective feedback

Did you provide corrective feedback? Did your corrective feedback include scaffolding appropriate for the learner? Did it result in the correct response from the learner and an opportunity to provide reinforcement? Provide one corrective feedback statement you used or could have used in the lesson. If you did not use corrective feedback, what is your next step?

Components of effective High leverage practices $8 \& 22$ explain that feedback can enhance learning. feedback How were you able to positively impact learning by using intentional feedback? How can you ensure your feedback meets all the components of effective feedback?

video clips of the preservice teacher where both the teacher educator and the preservice teacher can review and provide in-depth feedback on a given instructional segment. From this feedback, the preservice teacher can reflect on their practice.

After viewing her lesson, Mariah is able to identify a location where she could have provided feedback to her student, Carly. "I noticed I missed an opportunity to provide instructive feedback when Carly correctly responded to the math problem. Had I linked her understanding to the upcoming topic, adding fractions, she would have had additional foundational knowledge. I made a note in my lesson plan so I wouldn't forget this potential opportunity when I teach the same lesson to Juan next week!'”

Free tools for recording and reflecting on practice such as a cell phone video shared via cloud storage, like Google Drive, can be more cumbersome but effective in recording and sharing videos. Example questions to direct deep, reflective practice on feedback are included in Table 2.

\section{Concluding Thoughts}

Through the use of multiple and varied opportunities such as modeling, practice, and reflection, desired teacher behaviors can be mastered by preservice teachers and generalized into the P-12 environment. The result of these intentional and ever evolving strategies are preservice teachers who have the power to be highly effective educators. The power lies not in the number of preservice teachers produced, but in the individuals adequately prepared to assess, design, and implement instructional sequences that positively impact the social, emotional, and academic well-being of diverse populations.

The goal of EPP's remains the same: We desire to produce exceptional educators. Yet the means by which this goal is obtained must shift hurriedly to meet the often-daunting realities of the P-12 classroom. By modeling best practice during coursework, providing multiple scaffolded opportunities for preservice teachers to demonstrate their skills in college classrooms and through aligned clinical field experiences, and teaching preservice teachers to be reflective of their actions, we are responding to the notion that what we have always done has not always worked. The implications of these intentional scaffolded opportunities are to ensure that EPP's are emphasizing the positive outcomes associated with feedback and ensuring that preservice teachers are able to successfully transfer these skills into the P-12 environment. Through consistent communication and collaboration with colleagues, university supervisors, and public-school partners, we can be united in producing exceptional educators who will use feedback to positively impact the learners they teach for years to come. 


\section{References}

Albarran, S. A. \& Sandbank, M. P. (2018). Teaching non-target information to children with disabilities: An examination of instructive feedback literature. Journal of Behavioral Education, 28(1), 107-140. https://doi.org/10.1007/s10864-0189301-3

Baer, D. M., Wolf, M. M., \& Risely, T. R. (1968). Some current dimensions of applied behavior analysis. Journal of Applied Behavior Analysis, 1, 91-97. https://dx.doi.org/10.1901\%2Fjaba.1968.1-91

Brock, M. E., \& Carter, E. W. (2017). A meta-analysis of educator training to improve implementation of interventions for students with disabilities. Remedial and Special Education, 38, 133-144. https://doi.org/10.1177/0741932516653477

Brownell, M. T., Benedict, A. E., Leko, M. M., Peyton, D., Pua, D., \& Richards-Tutor, C. (2019). A continuum of pedagogies for preparing teacher to use high-leverage practices. Remedial and Special Education, 406(6), 338-355. https://doi. org/10.1177/0741932518824990

Dreyfus, S. E. (2004). The five-stage model of adult skill acquisition. Bulletin of Science, Technology\& Society, 24(3), 177-181. http://dx.doi. org/10.1177/0270467604264992

Etscheidt, S., Curran, M., Sawyer, C. (2012). Promoting reflection in teacher preparation programs: A multilevel model. Teacher Education and Special Education, 35, 7-26. http://doi. org/10.1177/0888406411420887

Grossman, P. L. (2005). Research on pedagogical approaches in teacher education. In M. Cochran-Smith \& K. Zeichner (Eds.), Studying teacher education (pp. 425-476). Mahwah, NJ: Lawrence Erlbaum.

Hattie, J. (2009). Visible learning: A synthesis of over 800 meta-analyses relating to achievement. Routledge.

Hattie, J., \& Timperley, H. (2007). The power of feedback. Review of Educational Research, 77, 81112. https://doi.org/10.3102/003465430298487

Hudson, M. E., Voytecki, K. S., \& Zhang, G. (2018). Mixed-reality teaching experiences improve preservice special education students' perceptions of their ability to manage a classroom. Journal for Virtual Worlds Research, 11(2), 1-18. https://doi. org/10.4101/jvwr.v11i2.7308

Kraft, M., Blazar, D., \& Hogan, D. (2018). The effect of teacher coaching on instruction and achievement: A meta-analysis of the causal evidence. Review of Educational Research, 88(4), 547-588. https://doi.org/10.3102\%2F0034654318759268

Markelz, A., Riden, B., \& Scheeler, M. C. (2017). Generalization training in special education teacher preparation: Does it exist? Teacher Education and Special Education, 40(3), 179193. https://doi.org/10.1177/0888406417703752

McLeskey, J., Barringer, M-D., Billingsley, B., Brownell, M., Jackson, D., Kennedy, M., Lewis, T., Maheady, L., Rodriquez, j., Scheeler, M. C., Winn, J., \& Ziegler, D. (2017). High-leverage practices in special education. Council for Exceptional Children \& CEEDAR Center.

Moylan, L.A., Johnson, E.S., Crawford, A.R., Zheng, Y. (2017). Explicit Instruction Rubric. Recognizing Effective Special Education Teachers (RESET), Boise State University: Boise, ID. https:// www.boisestate.edu/education-reset/

Myers, D. M., Simonsen, B., \& Sugai, G. (2011). Increasing teachers' use of praise with a response-to-intervention approach. Education and Treatment of Children, 34 (1), 35-39. https:// www.jstor.org/stable/42900100

National Council for Accreditation of Teacher Education. (2010, November). Transforming teacher education through clinical practice; A national strategy to prepare effective teachers. Washington, DC: Blue Ribbon Panel on Clinical Preparation and Partnerships for Improved Student Learning. http://www.ncate.org/LinkClick.aspx?fileticket $=$ zzeiB1 $)$ oqPK\%3D\&tabid $=7 \mathrm{i}$

Peterson-Ahmad, M. (2018). Enhancing preservice special educator preparation through combined use of virtual simulation and instructional coaching. Education Sciences, 8(1), 10. https://doi. org/10.3390/educsci8010010

Royer, D. J., Lane, K. L., Dunlap, K. D., \& Ennis, R. P (2019). A systematic review of teacher-delivered behavior-specific praise on $\mathrm{K}-12$ student performance. Remedial and Special Education, 40(2). 112-128. https://doi. org $/ 10.1177 / 0741932517751054$

Skinner, C. H., Fletcher, P. A., \& Henington, C. (1996). Increasing learning rates by increasing student responses rates: A summary of research. 
School Psychology Quarterly, 11(4), 313-325.

https://doi.org/10.1037/h0088937

Thomas, C. N., \& Rieth, H. J. (2011). A research synthesis of the literature on multimedia anchored instruction in preservice teacher education. Journal of Special Education Technology, 26(2), 1-22. https://doi.org/10.1177/016264341102600201

Waack, S. (2018). Hattie ranking: 252 influences and effect sizes related to student achievement. https://visible-learning.org

Werts, M. G., Wolery, M., Gast, D. L., \& Holcombe, A. (1996). Sneak in some extra learning by using instructive feedback. Teaching Exceptional Children, 28, 70-71. https://doi. org/10.1177/004005999602800315

\section{About the Authors}

\section{Kera Ackerman}

Kera Ackerman, Ph.D. is an assistant professor of special education in the College of Education at the University of Kentucky. Her research interests include pre and in service teacher training and the use of high leverage and evidence-based practices in college and P-12 special education and inclusive classrooms.

\section{Channon Horn}

Channon Horn, Ph.D. is an associate clinical professor of special education in the College of Education at the University of Kentucky. Her research interests include active student engagement strategies, pre-service teacher training, and the use of evidenced-based practices to enhance the academic and behavioral outcomes for learners with differences. 